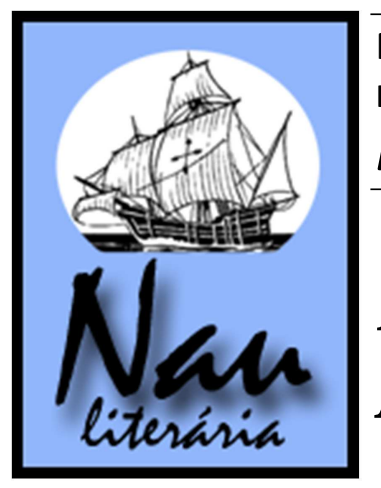

\title{
A estilística do pensamento em Natália, de Helder Macedo
}

Jean Kartabil Loregian*

\begin{abstract}
Resumo: Este texto apresenta a possibilidade de leitura do romance Natália, de Helder Macedo, por uma ótica das figuras de linguagem, em especial o oximoro. Mas outras figuras também são importantes, como, por exemplo, a metáfora e a metonímia. A livre observação do leitor a partir dessa visão estilística é o resultado esperado.
\end{abstract}

Palavras-chave: Estilística, oximoro, metáfora e metonímia, ambiguidades, estranhamento.

\begin{abstract}
This text presents the possibility of reading the novel Natalie, from Helder Macedo, for a perspective of figures of speech, especially the oxymoron. But other figures are important too, for example the metaphor and metonymy. The free observation of the reader per this style vision is the expected result.
\end{abstract}

Keywords: Stylistic, oxymoron, metaphor and metonymy, ambiguity, strangeness.

Por diversas vezes, durante a leitura de Natália, percebi, ainda por ora sem motivo aparente, um estranhamento, um conflito que ultrapassava as personagens e vinha direto a mim. Na maioria das vezes, esse estranhamento estava diretamente ligado à própria Natália, noutras, era sentido através de Paulo, Jorge, o avô ou Fátima, isto é, basicamente todas as personagens causavam esse estranhamento. Esse sentimento não estava associado diretamente a elas, mas a uma forma de linguagem latente nas entrelinhas do diário de Natália.

A utilização das figuras de linguagem tem a capacidade de violar os sentidos do leitor menos atento, fazendo com que questione, ou não, o motivo pelo qual faz parecer que está caminhando por um lugar nebuloso, em que os fatos parecem expandir-se em dualidades. Caso o leitor não perceba o empenho do escritor em deslocar a linearidade da obra a um nível de suspense de competência estilística, da possibilidade que se tem em trabalhar o romance dessa forma, em nada estará comprometido o entendimento do todo, contudo, é curioso fato que se perde o que ali está e pode ser observado.

Basicamente as figuras de linguagem são sutis, mas no decorrer dos acontecimentos o escritor joga muito com elas. As personagens são ambíguas, em especial Natália; são compostas, supostamente, de sua cara metade às avessas, que se excluem mutuamente: avô/avó, os pais, Paulo/Jorge, Natália/Fátima. Em outras palavras, a característica do duplo é

\footnotetext{
* Graduando em Letras (UFRGS).
} 
evidente na obra e amplificada na personagem Natália. Dentre todas as personagens, ela é a que fica marcada por esse caráter. Seus pensamentos são incertos e inseguros.

Como se formam essas ambiguidades? Os pais de Natália eram revolucionários ou terroristas? $\mathrm{O}$ avô era cúmplice da ditadura ou praticou um ato de generosidade vingativa ao auxiliar no crescimento de Fátima, filha do assassino dos pais de Natália? É plausível que as figuras de linguagem, e nesse aspecto dualístico é mister atribuir maior parte dos créditos ao oximoro, interfiram substancialmente na quebra dessa linearidade, no contraste do sim com o não, da dupla interpretação constante em que o romance se edifica, deixando à parte os fatos interagidos explicitamente com o leitor. As figuras de linguagem têm função tangente no que diz respeito ao enredo, mas são visíveis e tocantes quando da percepção das mesmas como parte fundamental do objetivo do escritor em provocar tais sentimentos de estranhamento ou jogo com o leitor.

O oximoro caracteriza-se por ser uma figura de pensamento que harmoniza dois conceitos opostos, formando assim um terceiro conceito, que dependerá muito da interpretação de quem estiver lendo. E é esse terceiro conceito que poderá transformar o óbvio em dúbio, havendo entre o sim e o não um talvez, especificamente no romance Natália, afinal em questão. Por isso, é de fundamental importância o seu apontamento, entretanto, seria um equívoco atribuir somente a ele, o oximoro, a concepção da ótica da estilística, pois toda e qualquer figura de linguagem encontrada no romance Natália é de fundamental relevância. Contudo, ainda, atribui-se a ele tamanha importância, pois essa suspensão de um terceiro conceito é visivelmente sobressalente em várias passagens da obra ou pensamentos das personagens. A metáfora e a metonímia também estão presentes no romance, mas a evidência conceitual do duplo é característica inerente à figura de pensamento oximoro.

É possível apontar algumas dualidades curiosas na obra, como, por exemplo, a morte do avô e da avó: o avô morrera tranquilo, "adormeceu na poltrona e não acordou. Talvez por já não ter mais histórias para contar. Tinha de ser. Com a avó foi diferente, morreu do cancro que já tinha." (MACEDO, 2010, p. 53). Aparentemente é uma ocorrência dualística com pouca relevância, no entanto, é notável a maior afinidade que Natália tem com o avô e menor com a avó, e essa percepção fica mais nítida para o leitor se levado em consideração o uso das figuras de linguagem. Para o escritor, é uma ferramenta disponível e de grande utilidade. Nesse trecho, a avó tem uma morte sofrida, enquanto o avô morreu dormindo, mas em todos os acontecimentos que envolvem os avós, o avô é o herói, o pai, a pessoa por quem se tem ciúmes. A avó não tem passado e no seu funeral não estava quase ninguém, apenas Natália, Paulo, Jorge, a empregada e a enfermeira dos últimos tempos. Com isso se estabelecem focos 
narrativos, já que o avô tem fundamental importância para a história. É preciso atribuir a ele um tratamento especial, que deixará o leitor sem saber a verdadeira intenção ao ajudar Fátima, se somente por generosidade, ou se essa generosidade era de uma forma de vingança.

Outro caso um pouco mais evidente desse jogo de ambiguidades é a relação entre Natália e Fátima. A crise de identidade que poderia afastá-las acaba por uni-las. Natália, a princípio, se sente ameaçada por Fátima, não sente nenhum afeto por ela, porém, aos pouco, ligam-se intimamente. Nestes trechos ficará claro o jogo do duplo, do bem e do mal que deixam o leitor a pisar em terreno minado, devido à inconstância de Natália: "Visita surpresa da Fátima Rua. Da mulher do Paulo. Da putéfia. Da ninfete do meu avô.” (MACEDO, 2010, p. 107) E, para fechar o circuito contraditório: "Senti, a contragosto, que não estava a desgostar da Fátima. Se calhar já nem sequer a contragosto. A ter pena dela. Não, se calhar não era pena. Era achar que ela era mais interessante do que eu julgava.” (MACEDO, 2010, p. 111) E essa é uma breve representação dos pensamentos de Natália em relação a Fátima, pois é constante essa dualidade, que também envolve o filho de Fátima, Diogo. Ora Natália não sente afeto nenhum pelo bebê, ora quer segurá-lo em suas mãos.

Se observado por essa ótica estilística, é curiosa a constância desses acontecimentos que envolvem metáforas, metonímias, oximoros, entre outras figuras de linguagem.

Roman Jakobson, em Linguística e Poética, resultado das suas conferências, escreve:

A supremacia da função poética sobre a função referencial não oblitera a referência, mas tornaa ambígua. A mensagem do duplo sentido encontra correspondência num remetente cindido, num destinatário cindido e, além disso, numa referência cindida, conforme o expõem convincentemente os preâmbulos dos contos de fada dos diversos povos, como, por exemplo, o habitual exórdio dos contadores de história de Majorca: Aixo era y no era ('isso era e não era'). (JAKOBSON, 1995, p. 150)

É pertinente a redução considerável da utilização das figuras de linguagem para a narrativa assumir um caráter referencial e as lacunas serem preenchidas, do contrário a proposta da obra pode não ser bem sucedida, e é essa suspensão das figuras de linguagem que pude observar a partir de um determinado momento no romance, logrando, assim, para um final adequado. Mas o interessante é que os acontecimentos inexplicáveis no romance acabam fortalecendo a proposta, e as numerosas dúvidas que ficam ao término da leitura decorrem inevitavelmente do autor ter plantado, durante o percurso narrativo, as sementes de uma estilística associada ao jogo dualístico. Não podemos esquecer que o percurso narrativo não é composto apenas por autor e leitor, mas que existe um narrador fictício, ou seja, Natália, e, além disso, uma gama de personagens que contribuem ativamente para tal jogo com o duplo 
sentido, apenas relembrando Roman Jakobson (1995) ao se referir sobre o "discurso dentro do discurso".

A pretensão deste trabalho foi sugerir uma leitura do estranhamento através de uma perspectiva estilística, ou seja, como a contradição, a ambiguidade, enfim, o jogo de duplo sentido, seja ele verbal, na disparidade entre as personagens, no mistério que as envolve ou no importantíssimo detalhe de que a própria obra não existe, pois é deletada ao final, como a utilização das figuras de linguagem potencializam o efeito de incerteza no leitor. Há ainda a hipótese de que a plena consciência dessa utilização pelo autor possibilita o avanço linear da história, formando assim uma unidade que abarca uma leitura natural da ordem dos fatos e uma leitura estruturada, mergulhada na metalinguagem.

\section{Referências}

MACEDO, Helder. Natália. Rio de Janeiro: Beco do Azougue, 2010.

JAKOBSON, Roman. Linguística e Comunicação. São Paulo: Cultrix, 1995.

JAKOBSON, Roman. Linguística. Poética. Cinema. São Paulo: Perspectiva, 1970.

MESQUITA, Roberto Melo. Gramática da Língua Portuguesa. São Paulo: Saraiva, 2002.

http://www.ufop.br/demet/metodologia.pdf - acesso em 30 de junho de 2011.

http://www.gargantadaserpente.com/linguagem/figuras.pdf - acesso em 30 de junho de 2011.

http://www.periodicos.ufsc.br/index.php/Outra/article/view/2176-8552.2010n10p91 - acesso em $30 \mathrm{de}$ junho de 2011. 